\title{
XIII \\ O PLURILINGUISMO E O CASO DOS ÍNDIOS WARAO EM SANTARÉM/PA ${ }^{* 1}$
}

\author{
Daniela Figueira Alano² \\ Ediene Pena Ferreira ${ }^{2}$
}

\section{Introdução}

Do ponto de vista linguístico, podemos dizer que o território brasileiro é caracterizado pela coexistência de diversas línguas, como as línguas indígenas, as línguas dos imigrantes, as línguas de fronteira, entre outras. A despeito dessa diversidade, o sistema educacional se caracteriza pela padronização e homogeneização linguística, visto ser a língua portuguesa a única considerada oficial em todo território brasileiro. Essa padronização é apoiada pelo projeto político de homogeneização do português, e cria a pretensa ideia de ser o Brasil um país monolíngue.

A noção de monolinguismo cunhada principalmente por Oliveira (2008; 2009), que afirma a necessidade de Políticas Públicas que tentem integrar alunos que falam outras línguas em nosso país. Para que isso ocorra, é necessário que se abandone a ideia de que existe apenas uma língua no país, e dessa forma abarcar as outras línguas na organização educacional. Desta maneira, o mito do monolinguismo, como o autor conceitua, pode ser evidenciado da seguinte forma:

Para compreendermos a questão é preciso trazer alguns dados: no Brasil de hoje são falados por volta de 215 idiomas. As nações in-

\footnotetext{
*DOI - 10.29388/978-65-86678-45-1-0-f.307-326

${ }^{1}$ Contribuíram para a realização desta pesquisa os acadêmicos do curso de Letras/Ufopa: Carlos Henrique Xavier de Aguiar; Natália R. A. Almeida; Breno Augusto Pena Ferreira; e a mestranda Cleylma Rodrigues Riker

${ }^{2}$ Mestranda em Educação do Programa de Pós-graduação em Educação da Universidade Federal do Oeste do Pará PPGE/UFOPA. E-mail: danielaalanostm@hotmail.com

${ }^{2}$ Doutora em Linguística. Professora do Instituto de Ciências da Educação da Universidade Federal do Oeste do Pará. E-mail: ediene.ferreira@ufopa.edu.br
} 
dígenas do país falam cerca de 180 línguas (chamadas de autóctones), e as comunidades de descendentes de imigrantes outras 30 línguas (chamadas de línguas alóctones). Some-se a estas ainda as línguas de sinais, com destaque para LIBRAS, língua brasileira de sinais, e para línguas afro-brasileiras ainda usadas nos quase mil quilombos o oficialmente reconhecidos no Brasil. Somos, portanto, um país de muitas línguas, plurilíngüe (OLIVEIRA, 2009, p.20).

Portanto, embora o idioma português seja a língua oficial do estado para as ações legais e formais do país, não se pode simplesmente ignorar a existência de tanta diversidade linguística em nosso território nacional. Para que isso aconteça, o primeiro passo é justamente compreender esse plurilinguismo e seus respectivos fenômenos. Diversos projetos trabalham neste sentido, é o caso do Observatório de Educação na Fronteira (OBEDF), que procura discutir confrontos entre a Língua Portuguesa e a realidade multilíngue nas escolas das fronteiras do Brasil com o Paraguai e a Bolívia (MORELLO, 2016).

Na cidade de Santarém, município do Pará, é possível observar de perto toda essa realidade de pluringuismo, uma vez que existem diversas comunidades indígenas na região, além de imigrantes venezuelanos. Segundo dados do site oficial da prefeitura de Santarém, a cidade se localiza na região oeste do estado do Pará, é a terceira mais populosa do estado, atrás apenas de Belém e Ananindeua. É o centro financeiro, urbano, cultural e comercial do Oeste do Pará, situando-se na confluência de dois importantes rios o Tapajós e o Amazonas. É conhecida como Pérola do Tapajós, e pertence à mesorregião do Baixo Amazonas.

Segundo Gomes (1997), a cidade de Santarém foi classificada como uma cidade no ano de 1848, embora seus primórdios sejam mais antigos. Depois que a cidade de Belém foi fundada, Pedro Teixeira, Frei Cristóvão, vários soldados e índios exploraram o Rio Amazonas, até chegarem à aldeia de Tupuliçus. Lá, desenvolveram boas relações com os índios e a povoação acabou crescendo. No ano de 1661, este local passou a ser conhecido como Aldeia de Tapajós. Com a ampliação desta área e a estruturação militar, a aldeia foi classificada como vila em 1758, receben- 
do o nome de Santarém, em homenagem à cidade portuguesa homônima, e pouco mais de 100 anos depois foi nomeada como cidade, devido a seu desenvolvimento.

Nos últimos anos, a cidade de Santarém vem recebendo um número considerável de imigrantes venezuelanos, sobretudo indígenas. Silva (2017) afirma que isso ocorre principalmente devido à crise econômica e social, à repressão e à violência às quais a Venezuela está sendo exposta devido a eventos sócio políticos. O Panamá, o Equador e o Chile têm recebido muitos imigrantes, assim como o Brasil. De acordo com o autor, Santarém é uma das cidades que mais recebe imigrantes no Brasil, por estar em uma região estratégica, com acesso por rodovias, rios ou aeronaves.

Essa imigração contribui para a diversidade linguística em Santarém, pois os imigrantes que chegam trazem consigo a sua língua. Segundo uma matéria de um jornal de 2017, uma grande quantidade de indígenas da etnia Warao chegou ao município no dia 28 de setembro desse ano. A maioria deles estava com fome e não tinham sequer roupas para se vestirem. Foram acolhidos por uma instituição de pessoas em situação de rua e depois por Igrejas Evangélicas. O governo municipal chegou a declarar emergência, com a alegação de que a cidade não tinha recursos para receber um número tão grande de refugiados.

Considerando essa realidade e a necessidade de realizar um mapeamento da realidade linguística da região, o Grupo de Estudos Linguísticos do Oeste do Pará - Gelopa, abrigado no Programa de Letras da Universidade Federal do Oeste do Pará, iniciou o projeto de pesquisa Diagnóstico sociolinguístico de escolas públicas do oeste paraense em contexto plurilíngue. De acordo com o relatório realizado pelo Gelopa, referente aos primeiros meses da pesquisa, os indígenas venezuelanos, pertencentes à etnia Warao, ficaram em abrigo, disponibilizado pela prefeitura, e crianças e jovens foram todos matriculados em escola próxima. Cerca de 40 venezuelanos foram matriculados na Escola Municipal Eloína Colares, que, por esse motivo se tornou lócus de pesquisa do grupo. De acordo com o Gelopa, os matriculados não possuem o domínio da Língua Portuguesa. Esses indígenas aumentarão o número de crianças e jovens que falam 
seus idiomas nativos sem dominar o português, tal como os Way-way da reserva Mapuera do município de Oriximiná

Os casos descritos anteriormente apenas colaboram para desacreditar no mito do monolinguismo abordado por Oliveira (2008; 2009), uma vez que é perceptível a diversidade linguística presente em todo o país. É fundamental a criação de estratégias para a transformação deste quadro, e o primeiro passo é justamente diagnosticar e observar o fenômeno do plurilinguismo nas escolas. Seguindo essa linha, a presente pesquisa acerca do plurilinguismo presente na escola Eloína Colares se justifica com base nestes argumentos, já que se faz necessária a análise do funcionamento diversificado da língua neste contexto em que se prioriza apenas uma língua.

O objetivo geral do presente estudo é o de descrever uma realidade linguística da amazônia paraense a partir de dados levantados por pesquisadores do Grupo de Estudos Linguísticos do Oeste do Pará no município de Santarém com a chegada dos imigrantes venezuelanos. Para tal, foi necessário identificar os alunos monolíngues, bilíngues e plurilíngues dentro do contexto escolar, além daqueles alunos que não dominam a língua portuguesa. Também se investigou o monolinguísmo e o bilinguismo dos próprios professores, de modo a diagnosticar a natureza desta diversidade. Foram observadas as origens dos alunos cuja língua materna não é o português, e qual função teria o português para os alunos bilíngues que possuem outra língua materna.

\section{O mito do monolinguismo em um país plurilíngue}

Para compreendermos a realidade linguística da cidade de Santarém, é necessário entendermos o mito do monolinguismo, já citado neste artigo. Oliveira (2008) demonstra que a população em geral e os linguistas reconhecem a existência de outras línguas no espaço brasileiro, o problema é a falta de políticas linguísticas que abarquem todas essas línguas em pleno funcionamento. $\mathrm{O}$ mito do monolinguismo, portanto, não é a falta de reconhecimento em relação a essas línguas, mas sim a aceitação do Português como a única língua a ser fomentada e mantida neste território. 
Segundo o autor citado, os próprios estudos linguísticos, muitas vezes, perpetuam essa relação multilíngue em nosso território. Ao abordar temáticas como "diversidade linguística", pode-se imaginar a própria diversidade existente na Língua Portuguesa, e muitas vezes não se leva em conta a diversidade de línguas nativas e estrangeiras no território brasileiro. Desta forma, a sociedade aceita a Língua Portuguesa como a "língua única" e todas as outras vão morrendo ao longo do tempo, por falta de falantes, estudiosos e professores dessa língua. Assim,

Quando se fala em diversidade lingüística muitas vezes se pensa
na diversidade interna à própria língua portuguesa, o que decorre,
entre outras razões, do predomínio, no país, de uma sociolingüísti-
ca de cunho laboviano que poderíamos chamar de “"sociolingüísti-
ca do monolingüismo"”. Mas este interesse é crescente, e pode aju-
dar as diversas comunidades lingüísticas do Brasil a manterem e
desenvolverem suas línguas (OLIVEIRA, 2008, p. 7)

Pode-se interpretar que essa sociolinguística de cunho laboviano é justamente o ato de estudar a língua predominante no território e observar sua variação. Por exemplo, é comum que os professores de Língua Portuguesa demonstrem, para seus alunos em sala de aula, que há variação regional no Brasil, já que há um modo de falar nordestino, sulista, carioca, e assim por diante. $\mathrm{O}$ autor não condena esse tipo de abordagem, pois ela é necessária para que os estudantes compreendam a riqueza e as multifaces da língua. No entanto, também é importante demonstrar que existem outras línguas, além do Português, sendo faladas o território brasileiro, com suas próprias variações, características e gramáticas.

Bassani (2015) realiza uma distinção entre os conceitos de bilinguismo, multilinguismo e monolinguismo. Segundo a autora, há duas maneiras de observar esses conceitos: de uma forma social e de uma forma individual. Em relação ao social, Bassani (2015) afirma que todos os cidadãos do mundo são no mínimo bilingues, pois é provável que não exista ninguém no mundo (nenhum adulto) que não saiba ao menos algumas poucas palavras que não pertençam a sua variedade materna. Isso ocorre em todos os países do mundo, já que todos eles possuem várias 
línguas em seu território. Segundo as estimativas, existem 6.700 línguas no mundo e 200 estados-nações oficiais. Esses números mostram claramente que existem mais línguas que países, mas as línguas oficiais nessas nações é, na maioria das vezes, apenas uma.

Portanto, no mundo inteiro parece que existe a ideia do monolinguismo, embora a realidade seja multilíngue. Bassani (2015) demonstra que esse mito é sustentado por razões políticas, tendo em vista que há um grupo dominante que escolhe a língua oficial daquele território e a impõe opressivamente a todos. No Brasil, por exemplo, existem aproximadamente 210 línguas, mas é a Língua Portuguesa padrão que o aluno precisa aprender na escola para se inserir no mercado de trabalho, na vida pública e na sociedade de maneira geral. Assim:

Apesar de quase todos os países incorporarem um grande número de grupos falantes de diversas línguas, como é o caso do Brasil, em muitos casos, apenas uma ou duas línguas são reconhecidas como oficiais. O fato de serem reconhecidas como oficiais implica em que serão línguas ensinadas na escola, nas instituições oficiais e nas instituições legitimadoras, como a mídia. Isso porque, no geral, os grupos politicamente mais poderosos de qualquer sociedade conseguem impor suas línguas aos grupos menos poderosos. Convenciona-se chamar de minorias linguísticas os grupos menos poderosos (BASSANI, 2015, p. 7).

Assim, o mito do monolinguismo é contraditório se observarmos a realidade plurilíngue e multilíngue do Brasil. Menezes (2013) demonstra que o plurilinguismo e o multilinguismo são usados, muitas vezes, como sinônimos, mas eles guardam algumas especificidades próprias. Segundo o autor, o plurilinguismo possui uma conotação que leva em consideração a estreita relação entre língua e cultura, enquanto o multilinguismo representa a diversidade linguística existente em um território e também a oferta de aprendizagem dessas línguas. Em outras palavras, o plurilinguismo leva em conta também a cultura que as línguas guardam. Neste sentido, o Brasil é um país plurilíngue e multilíngue, já que existem diversas línguas neste território geográfico, ao passo que também existem pessoas com múltiplos aspectos culturais. 
É necessário ressaltar que a Declaração Universal dos Direitos Linguísticos, elaborada pela UNESCO, estipula que qualquer indivíduo possa se expressar linguística e culturalmente, de acordo com seus costumes maternos. Além disso, o documento é enfático no que diz respeito à assimilação, ou seja, quando um povo abandona sua língua materna pelo uso de outra, condenando a indução dessa prática. Ou seja, os indivíduos devem ser livres para utilizarem a língua dominante de um país ou não. No artigo de número 4 , há o seguinte texto:

Por outro lado, esta Declaração considera que a assimilação — entendida como a aculturação das pessoas na sociedade que as acolhe, de tal maneira que substituam as suas características culturais de origem pelas referências, pelos valores e pelos comportamentos próprios da sociedade de acolhimento - em caso nenhum deve ser forçada ou induzida, antes sendo o resultado de uma opção plenamente livre (UNESCO, 1996, p. 6)

Esta é uma Política Linguística interessante, que valoriza a diversidade cultural de qualquer região. O problema é que, infelizmente, as orientações da Declaração não estão sendo devidamente aplicadas em território brasileiro e, na maioria das vezes, não são nem conhecidas. Não se pode afirmar que a língua portuguesa não é induzida aos praticantes de outras línguas no espaço nacional, uma vez que a Escola é constituída pelo mito do monolinguismo, e tenta padronizar os alunos através dessa língua, negando-lhes a oportunidade de praticar sua língua materna.

Oliveira (2008) demonstra que essa imposição da Língua Portuguesa em relação aos indivíduos que vivem no Brasil não é recente, acontece desde que os Europeus invadiram essas terras. É preciso relembrar que os portugueses forçaram sua língua para os nativos, e diversos dialetos foram apagados devido a essa violência cultural. Com o passar dos séculos, essa política não mudou, e o Estado continuou impondo a Língua Portuguesa de forma violenta, chegando a proibir o uso de qualquer outra língua durante algum tempo de nossa História. Hoje, essa opressão é menos violenta, mas ainda é coercitiva, pois muitos indivíduos sofrem 
preconceito e outras represálias se não falarem a Língua Portuguesa. Assim,

A História nos mostra que poderíamos ter sido um país ainda muito mais plurilíngüe, não fossem as repetidas investidas do Estado contra a diversidade cultural e lingüística. Essa mesma História nos mostra, entretanto, que não fomos apenas um país multicultural e plurilíngüe: somos um país pluricultural e multilíngüe, não só pela atual diversidade de línguas faladas no território, mas ainda pela grande diversidade interna da língua portuguesa aqui falada, obscurecida por outro preconceito: o de que o português é uma língua sem dialetos (OLIVEIRA, 2008, p. 8)

Desta forma, pode-se afirmar que o Estado foi e ainda é um dos principais responsáveis por perpetuar o mito do monolinguismo, fazendo com que a diversidade de línguas presentes em nosso território seja diariamente oprimida. Essa realidade pode ser observada de perto na educação amazônica, já que há um número expressivo de línguas nativas faladas na região, mas as escolas, pautadas nessa política linguística opressora, acabam por vezes padronizando a língua dos estudantes e minguando as línguas nativas.

Segundo Colares (2012), essa política não é nova na região, e foi iniciada com a expansão de Portugal na região, fomentada no Grão Pará. Essa campanha foi articulada com os desejos da Igreja Católica, que almejava converter os habitantes da área e "civilizar" a área. O autor demonstra que a política é vista como uma intencionalidade individual que busca realizações e, neste ponto de vista, somos seres políticos por natureza. $\mathrm{O}$ ato de tentar impor uma língua ou religião a falantes de outra língua, com outros credos, também se caracteriza enquanto um ato político.

Colares (2012) demonstra que na Amazônia colonial, a educação era quase um sinônimo de catequese, na qual a Igreja e os colonizadores tentavam impor a língua e fazer com que os nativos se tornassem obedientes e vendessem sua força de trabalho. Essa política fez com que diversas línguas nativas fossem apagadas, bem como a cultura de vários povos que foram oprimidos, catequizados, mortos ou escravizados. 
Mesmo que os tempos contemporâneos sejam diferentes, observamos que a história se repete, e a valorização da diversidade linguística existente na região ainda não é uma prioridade. Ano após ano, as línguas nativas diminuem cada vez mais devido à assimilação da Língua Portuguesa e ao mito do monolinguismo pregado pela Escola estatal. Somente com a aceitação da realidade plurilíngue da Amazônia e do Brasil é que se pode promover o multilinguismo existente em nosso país através de políticas linguísticas.

\section{Metodologia}

Este capítulo tem por propósito apresentar os primeiros resultados do projeto de pesquisa Diagnóstico sociolinguístico de escolas públicas do oeste paraense em contexto plurilingue, desenvolvido pelo Gelopa, coordenado pelo professora Dra. Ediene Pena Ferreira e desenvolvido pelos integrantes do grupo sendo eles os graduandos: Breno Augusto; Carlos Henrique Xavier de Aguiar Pena Ferreira; Natália R. A. Almeida e as mestrandas Cleylma Rodrigues Riker e Daniela Alano. A seguir apresentaremos como a pesquisa foi desenvolvida. O projeto iniciou seguindo a metodologia qualitativa, investigativa e bibliográfica, através do viés do diagnóstico sociolinguístico. Primeiramente, realizou-se um levantamento de toda a bibliografia a respeito da temática do monolinguismo, plurilinguismo, multilinguismo e políticas linguísticas, dando preferência àquelas que se relacionavam com a realidade paraense. Posteriormente, os pesquisadores realizaram uma investigação a respeito das escolas municipais de Santarém.

Segundo Seiffert (2014), o método do diagnóstico sociolinguístico consiste basicamente em analisar as línguas funcionando em um espaço geográfico, de forma diacrônica e sincrônico, considerando também aspectos culturais que influenciam esse funcionamento. $\mathrm{O}$ diagnóstico sociolinguístico é interdisciplinar, pois se apoia em conceitos da sociologia e da linguística, levando em consideração que a língua é um fenômeno social, e precisa ser observada em seu contexto de uso. Dessa forma, o diagnóstico é importante para o planejamento de políticas linguísticas e 
para a identificação das línguas em uso na escola e seus modos de circulação (MORELLO, 2016).

Assim, a próxima etapa da pesquisa foi justamente mapear as escolas que receberam ou recebem alunos falantes de outras línguas, sobretudo línguas de indígenas brasileiros e venezuelanos. A Escola Municipal de Santarém Eloína Colares, no bairro Ipanema, foi escolhida inicialmente para a elaboração do estudo. Foram aplicados alguns questionários e entrevistas semiestruturadas a gestores, professores e alunos. Todos os dados foram reunidos e analisados qualitativamente e interpretado à luz do referencial teórico reunido para a pesquisa. Os resultados foram cuidadosamente estruturados na forma do presente artigo científico.

\section{A realidade plurilinguística de Santarém}

A região de Santarém sempre foi plurilinguística, uma vez que, além da Língua Portuguesa, existem diversas comunidades indígenas falantes de línguas nativas e que frequentam as instituições públicas de educação. Essa realidade ficou mais complexa com a chegada de diversos indígenas da etnia Warao que vieram da Venezuela e passaram a frequentar essas mesmas instituições. Os Warao são uma etnia indígena que habita a região do nordeste da Venezuela e norte das guianas, têm uma língua e culturas próprias. As primeiras migrações em massa ocorreram no ano de 2017, e desde então a cidade de Santarém vem recebendo cada vez mais refugiados Warao.

Segundo matéria do G1 $(2017)^{3}$, os indígenas Warao fugiram da Venezuela devido ao regime ditatorial de Nicolás Maduro, e buscaram abrigo em vários países da América Latina, como Panamá, Equador e Chile. O Brasil também foi um dos países escolhidos como refúgio, e diversas famílias cruzaram a fronteiras do Brasil com a Venezuela e se estabeleceram em vários estados do Norte. Santarém foi uma das cidades que mais recebeu refugiados, devido ao seu fácil acesso pelas águas, ar ou terra. Muitos venezuelanos seguiram mais para o sul e outros permaneceram na cidade.

\footnotetext{
${ }^{3}$ Disponível em: https://g1.globo.com/pa/santarem-regiao/noticia/santarem-decreta-situacaode-emergencia-social-devido-a-presenca-de-refugiados-venezuelanos.ghtml
} 
De acordo com informações da matéria, a prefeitura acolheu os refugiados, que foram levados a um abrigo para pessoas em situação de rua. Alguns também foram abrigados pela Igreja, que ofereceu estadia e alimentação. Após se estabelecerem, diversas crianças Warao foram matriculadas em instituições educacionais da região, sendo que a escola municipal Eloína Colares foi a única que recebeu dezenas de indígenas Warao. Algumas crianças falavam o idioma nativo e o Espanhol, outras se comunicavam apenas com a Língua Materna, sendo um desafio para os professores.

A presente pesquisa foi realizada na escola Eloína Colares, e a partir de agora serão elencadas todas as observações e resultados de entrevista realizados na instituição pode meio de relatórios feitos pelos pesquisadores do Gelopa. Primeiramente, é interessante pontuar que há contatos entre os indígenas venezuelanos, tanto os da escola Eloína, como os do Abrigo, com falantes da língua portuguesa. As informações obtidas na escola Eloína pelos pesquisadores do Gelopa mostram que os alunos que lá estavam costumeiramente se direcionavam ao centro da cidade com seus pais para realizar o que chamam de "coleta" (pedir dinheiro). Neste contexto pode-se observar uma certa necessidade de comunicação. Para que os indígenas Venezuelanos peçam o dinheiro, precisam estabelecer de alguma forma interação com os falantes de língua portuguesa e aprender a outra língua a partir de uma necessidade social.

No abrigo, os indígenas venezuelanos têm celular e televisão, o que configura uma espécie de imersão dos indivíduos que falam Warao no universo da língua portuguesa. A televisão está em língua portuguesa e o celular, mesmo que alterado para espanhol, ainda representa um afastamento do Warao. Na escola Eloína verificou-se que existiam crianças em idades iniciais. A julgar pela idade, talvez nem estivessem letradas em seu próprio idioma e, por conseguinte, não estivessem minimamente a par de sua história, o que os constitui como indivíduos. Em outras palavras, estão em outro país, imersos em outra língua, que pode se constituir enquanto língua materna, já que elas não têm idade para dominar totalmente o Warao.

Dito isto, é possível questionar: como se dá a interação entre professores que falam a língua portuguesa e alunos que falam Warao, e que 
tiveram (nem todos) o mínimo contato com o espanhol? A resposta pode ser observada em Oliveira (2009), tendo em vista que essa interação vem de pressões linguísticas advindas de demandas sociais, já que muitos indígenas venezuelanos precisam interagir para conseguir dinheiro, para conseguir abrigo. Diversos já estão tendo contato com os meios de comunicação do país, que necessariamente interagem por intermédio da língua portuguesa.

Assim, de forma involuntária, por necessidades sociais e pelo mero fato de estarem no Brasil. Eles interagem ou precisam interagir de alguma forma, e essas tentativas contribuem para que formulem um arcabouço Linguístico que não é essencialmente organizado, mas que contribui para que os alunos entendam minimamente o que a professora está dizendo ou tentando dizer. Vale ressaltar que essa é uma forma velada de indução a adesão de uma nova Língua, algo que vai contra a Declaração dos Direitos linguísticos elaborada pela UNESCO, a qual mencionamos anteriormente.

Foi possível perceber que a professora, quase sempre que tentava falar com os alunos, buscava ao máximo dar ênfase às palavras mais importantes na interação. Sempre em seus atos de fala pontuava palavras essenciais para a interação, normalmente substantivos e verbos. Pouco se dava ênfase na gramática e palavras que demandam um conhecimento estruturado da língua, como as proposições "de" e "em".

Na escola Eloína Colares, no ano de 2019, estavam matriculados 505 alunos, sendo 40 da etnia Warao. Foram feitas, de maio a dezembro de 2019, 6 visitas na escola. As observações mostram que os alunos da etnia Warao, na faixa etária que varia de 6 a 19 anos, estavam reunidos todos na mesma sala, sendo alfabetizados por apenas uma professora e uma auxiliar. Os alunos, em sua maioria, pertenciam ao mesmo grupo familiar, o que influenciava na frequência às aulas e na evasão escolar, pois quando a família decidia migrar para outra cidade a quantidade reduzia bastante. Em agosto de 2019, de 40 alunos havia apenas 5, e estes pertenciam a mesma família que estava na iminência de também partirem.

As professoras utilizavam livros pedagógicos como o do programa "Se liga", que eram próprios para a alfabetização, além de uma metodologia adequada por partes das docentes que possibilitou os alunos ve- 
nezuelanos absorverem boa parte do conteúdo quando comparado com alunos de tinham o Português como língua materna. A maioria dos alunos tem uma noção de espanhol, e por isso as professoras falavam "portunhol", uma junção do Português com o Espanhol. Na sala havia cartazes com algumas palavras ou expressões na língua Warao, pois a intenção era fazer os alunos se sentirem à vontade, além de não perderem ou esquecerem a sua Língua.

Algumas crianças já possuem certa interatividade com a língua portuguesa, pois já estão mais tempo no país. Algumas crianças acompanhavam as mães na atividade de coleta (o ato de pedir dinheiro nos centros da cidade), o que potencializa a interatividade por meio da língua portuguesa. Por uma questão cultural, as crianças sentem a necessidade de estar juntas dos parentes, e por isso a professora afirmou que dificilmente se conseguia manter irmãos e primos longe uns dos outros. Segundo a professora entrevistada, os pais tinham grande anseio de ver os filhos na escola, para que aprendessem a escrever os nomes e começar a organizar os documentos.

$\mathrm{Na}$ sala de aula, a professora, para conseguir interagir com os alunos, utilizava bastante da linguagem gestual a cada ato de fala, como se estivesse desenhando o que estava enunciando. Em alguns outros momentos a docente chegava alterar o ato de fala, mesclando o espanhol e o português. A instrutora tentava também ser bem enfática a cada palavra, reforçando cada ponto de transmissão de informações para que fosse compreendida pelos alunos falantes da língua "warao". Este contexto reflete um choque entre culturas, línguas e formas diferentes de pensar e simbolizar o mundo. Este choque é complexo, mas que tende a ser profícuo, desde que existam políticas linguísticas adequadas, configuradas por pesquisas, como esta, que busca entender os diversos contextos sociolinguísticos.

Dos 40 alunos da sala, foi aplicado um questionário a 14, correspondendo a $35 \%$ da turma, por serem estes o que tinham condições de compreender e responder as perguntas. A maioria deles ainda contou com ajuda de colegas e da professora. Os alunos pertencem majoritariamente ao mesmo grupo familiar e, por serem nômades, isto influenciou uma grande evasão no segundo semestre ao ponto de a turma ficar com 
apenas 5 alunos, aumentando para 8 em seguida. No segundo semestre houve redução da turma e saída da Professora auxiliar. O baixo número de alunos e a saída do professor da turma do $1^{\circ}$ ano levou a Direção a unir a turma dos alunos warao, que permaneceu apenas com uma professora.

Portanto, as duas turmas estavam na mesma sala e a Professora tinha o duplo desafio de alfabetizar os dois grupos de alunos. As duas turmas juntas somavam cerca de 30 alunos. Após observarmos o elevado número de evasão escolar, visitamos o Abrigo Municipal e verificamos que o Município oferece boa estrutura e bom atendimento aos imigrantes. $\mathrm{Na}$ última visita os alunos não possuem documentação pessoal e tampouco documentação escolar, e talvez por isso não foram inseridos no sistema de matrículas, pois o Município de Santarém não possui turmas multisseriadas.

A partir das visitas percebemos que, embora o Município de Santarém seja referência em relação ao recebimento e atendimento aos diversos imigrantes, em especial os venezuelanos (por isso, muitos retornam para o Município após fazerem tentativas em outros lugares), no que se refere ao processo educacional, a Semed propõe inserção e interação dos alunos imigrantes. Todavia, ficou perceptível que falta um projeto efetivo de política linguística, sobretudo com preparação de professores para atuarem e liderem com estes alunos e outros em específico.

Embora o Ministério Público recomende que haja um estudo voltado para a situação dos imigrantes e atendimento aos mesmos, no que se refere ao ensino, o fato dos venezuelanos serem nômades, traz uma série de implicações e dificuldades ao sistema de ensino brasileiro. Não há uma aceitação de que estes alunos em situação de matrícula regular fiquem dois ou três meses fora da escola e depois retorne normalmente à sala de aula e continue seus estudos. Mesmo diante de todas as dificuldades enfrentadas pelos alunos indígenas venezuelanos como o choque cultural, linguístico e social, inseridos em um contexto totalmente diferente e atípico, eles surpreenderam e se sobressaíram em atenção, desempenho, dedicação, evolução e resultados frente aos alunos brasileiros. 
Para compreendermos essa realidade de forma mais aprofundada, colocaremos aqui os resultados dos questionários aplicados aos alunos imigrantes da Escola Eloína Colares. Dos 14 alunos que participaram, 7 eram do sexo masculino e 7 do sexo feminino, tinham entre 11 e 19 anos. Sobre os locais de nascimento, afirmam ser oriundos de Tucupita, Mariosan, Venezuela ou Baranca. A respeito da língua que dominam, todos os eles dominam o Warao, todos afirmam falar espanhol, 5 afirmam falar um pouco o português e o restante confirmam que falam bem o português. A respeito do local em que residem, todos afirmaram que estão morando no abrigo com a família, que inclui pai, mãe, irmãos e avós.

Sobre o tempo em que estão em Santarém, todos disseram que estão na cidade desde 2018, variando o mês. Sobre o local de onde vieram, as respostas incluíram quatro locais: Venezuela, Punta Pescador, Boa vista e Manaus. Em relação aos acompanhantes, as crianças afirmaram que vieram com a família, pais, irmãos e avós. Quando foram questionados sobre a língua que os irmãos falavam, 6 disseram que era somente Warao, 1 disse que era Warao e Português e 4 disseram que era Warao e Espanhol.

Eles também foram questionados em relação à Língua que se fala em casa. 6 disseram que se falava somente Warao e 4 disseram que se falava Warao e Espanhol. Ou seja, a Língua Portuguesa não é utilizada no âmbito íntimo dos imigrantes. Sobre o tempo em que estão na escola, disseram que desde fevereiro de 2019. Também se perguntou se eles frequentavam escola no local em que moravam, somente 1 não frequentou. Todos responderam que não tinha pais alfabetizados, no máximo escreviam o próprio nome.

Quando questionados se eles sabiam ler e escrever, todos afirmaram positivamente, com exceção de 2 . Dos que sabiam ler e escrever, todos eram alfabetizados em Warao e alguns afirmaram ler em espanhol e português. Todos concordaram que a Língua Portuguesa é difícil, mas bonita. Ao serem questionados sobre a língua falada com os colegas de sala de aula, todos afirmaram que falavam em Warao, e 4 afirmaram que utilizavam o Warao e Espanhol. Também responderam que se comunicam com os professores através do portunhol, uma mistura de português com espanhol. 
Fora da sala de aula, todos os entrevistados ficam no abrigo, e um deles disse que fica no centro. Dos 14 entrevistados, 9 deles afirmaram que saem para passear, somente 1 negou. 1 disse que passeia no Shopping, 7 passeiam no centro, 1 passeia na praça, 1 passeia no abrigo e 1 passeia pelas ruas. Nesses locais citados, 6 falam Warao, 5 tentam falar português, e 2 falam espanhol. Sobre a cidade, 6 falaram que é boa e 4 disseram que gostam muito, uma disse que quer ficar e nunca mais voltar de onde veio. 8 disseram que não querem mais voltar para a Venezuela, um disse que quer voltar e um disse que quer voltar apenas no próximo ano.

Sobre a língua materna, 4 disseram que é fácil, e 5 disseram que gostam muito do Warao. 8 deles disseram que gostam da escola e 2 disseram que é legal. Quando questionados sobre o que gostam, as respostas foram: da sala de aula, do parquinho, professora, dos colegas, lanche, escrever ler e desenhar. Sobre o que não gostam, a maioria disse que gosta de tudo, e um disse que não gosta da ausência dos colegas. A maioria considera a professora legal ou boa. Sobre a matéria que eles possuem mais dificuldade, a maioria disse que é a Língua Portuguesa, um disse tudo e um disse que não possui dificuldades. Também perguntamos que língua eles usariam na escola, se pudessem escolher, e todos disseram que usariam o Warao, mas deixaram claro que querem aprender a língua portuguesa.

Quando estão juntas e no convívio familiar, elas falam a mesma língua, o "warao". Entretanto, são motivadas pelos pais, especialmente os que pretendem ficar e fixar residência, a aprenderem o Português, para trabalharem e "não serem enganados" (assim eles dizem). É sabido que a Constituição Federal (CF/1988) determina que toda criança tem direito à educação, contudo, as diversas leis que regem as políticas educacionais em nosso País ainda não atendem à realidade plurilíngue, pois o ensino ainda é monolíngue, voltado para o público homogêneo, desconsiderando a existência e o crescimento do público heterogêneo.

Diante das observações, podemos concluir que a emigração dos venezuelanos para Santarém evidenciou a falta de uma política linguística efetiva e atenciosa para com os estudantes, e sobretudo com as docentes. Mesmo auxiliadas por materiais pedagógicos, na sala de aula há circuns- 
tâncias cujas procedências não constam nos livros, como foi esse caso, com alunos cuja língua materna era outra, oriundos de um contexto emigratório delicado, com uma cultura e vida diferentes. Além de tudo isso, por serem nômades, havia a dificuldade de ver o resultado do ensino, o que afetava não só a sala, como também a escola.

Casos como esse tendem a se repetir, por isso uma política linguística se faz necessária para que os emigrantes tenham sua cultura respeitada e para que os docentes tenham uma base de como proceder em determinadas situações e em relação a melhores metodologias aplicáveis. Essas medidas garantem que a escola não seja prejudicada e, sobretudo, que haja ainda mais interação e conhecimento cultural.

\section{Conclusão}

O presente trabalho buscou compreender uma realidade plurilíngue do município de Santarém mais especificamente da escola Eloína Colares, tendo em vista que existe o mito do monolinguismo inserido pelas políticas educacionais vigentes. Assim, entendeu-se que o plurilinguismo é justamente o entendimento de que nosso país é constituído por um espaço de muita diversidade cultural e linguísticas, onde vivem indivíduos que falam línguas nativas e estrangeiras e não apenas o Português. No entanto, a institucionalização do monolinguísmo incute a ideia de nosso país fala uma única língua, ceifando a possibilidade de abarcar essa diversidade.

Assim, através de uma observação empírica na escola Municipal Eloína Colares, nota-se que as instituições educacionais da cidade de Santarém vêm recebendo diversos imigrantes nativos Warao, que vêm da Venezuela em busca de uma vida melhor. Apesar de as professoras se esforçarem muito para oferecerem a melhor educação possível às crianças, nota-se a falta de um amparo estatal para suprir essa crescente necessidade. Ao entrevistar os alunos, percebemos que eles querem aprender o português, mas, neste processo, podem perder sua língua materna.

Portanto, é de extrema importância a criação de políticas linguísticas de caráter público que tenha um olhar empático para esta população, já que possuem suas línguas maternas, querem aprender a língua 
portuguesa, mas para isso não precisam abandonar sua língua e sua cultura. O primeiro passo para alcançar esse estágio é justamente com a compreensão de que estamos imersos em um contexto plurilíngue, e a tentativa coercitiva de impor a língua portuguesa a populações minoritárias é opressiva.

\section{Referências}

BASSANI, Indaiã de Santana. Fundamentos linguísticos: bilinguismo e multilinguismo. São Paulo: UNIFESP, 2015.

BRITO, Geovane. Santarém decreta situação de emergência social devido a presença de refugiados venezuelanos. G1, 2017. Disponível em: $<$ https://g1.globo.com/pa/santarem-regiao/noticia/santarem-decreta-situacao-de-emergencia-social-devido-a-presenca-de-refugiados-venezuelanos.ghtml>. Acesso em 24 de junho de 2020.

COLARES, Anselmo Alencar. História, Política e Educação na Amazônia colonial. Universidade Federal do Oeste do Pará, 2012.

GOMES, Denise Maria Cavalcante. Bibliografia sobre a cultura Santarém: história e perspectivas. Revista do Museu de Arqueologia e Etnologia, 1997. Disponível em: < https://www.revistas.usp.br/revmae/article/download/ 109306/107802 >. Acesso em 24 de junho de 2020.

MENEZES, Leonarda Jacinto José Maria. Plurilinguismo, Multilinguismo e Bilinguismo: Reflexões sobre a Realidade Linguística Moçambicana.

UFES, 2013. Disponível em: < http://periodicos.ufes.br/percursos/article/viewFile/4589/4578 >. Acesso em 04 de julho de 2020.

MORELLO, Rosângela; MARTINS, Marci F. Observatório da Educação na Fronteira: Política Linguística em Contextos Plurilíngues: desafios e perspectivas para a escola (Florianópolis), 2016. Disponível em: https://drive.google.com/file/d/1CRbWHheOaZm-WOXl68WuSBAnTgroKTKE/ view. Acesso em 05 de julho de 2020

OLIVEIRA, Gilvan Müller de. Plurilingüismo no Brasil. Representação Unesco no Brasil: Brasília, 2008.

OLIVEIRA, Gilvan Müller de. Plurilinguismo no Brasil: resistência linguística. Synergies Brésil nº 7, 2009. 
PROJETO Diagnóstico Sociolinguístico de Escolas Públicas do Oeste Paraense em Contexto Plurilíngue. Grupo de Estudos Linguísticos do Oeste do Pará Gelopa, 2018.

SANTARÉM. Site oficial da Prefeitura Municipal de Santarém. 2020. Disponível em: < http://www.santarem.pa.gov.br/pagina.asp?id_pagina=6>. Acesso em 24 de junho de 2020.

SEIFFERT, Ana Paula. Censos, Diagnósticos, Inventários e Observatórios Linguísticos: aspectos metodológicos e papel político linguístico. Tese (doutorado) em linguística. Universidade Federal de Santa Catarina, Centro de Comunicação e Expressão. Florianópolis, 2014.

SILVA, Sidney Antônio da. Indígenas venezuelanos em Manaus uma abordagem preliminar sobre políticas de acolhimento. Investigações geográficas, 2017. Disponível em: < https://scholar.google.com.br/scholar?hl=ptBR\&as_sdt $=0 \% 2 \mathrm{C} 5 \& \mathrm{q}=$ hist $\% \mathrm{C} 3 \% \mathrm{~B} 3 \mathrm{ria}+\mathrm{Santar} \% \mathrm{C} 3 \% \mathrm{~A} 9 \mathrm{~m} \& \mathrm{btnG}=>$. Acesso em 24 de junho de 2020.

UNESCO. Declaração Universal dos Direitos Linguísticos. Tradução de Wanda Ramos. Barcelona, 1996. 
